Case Report

\title{
Severe Wound Infection with Photobacterium damselae ssp. damselae and Vibrio harveyi, following a Laceration Injury in Marine Environment: A Case Report and Review of the Literature
}

\author{
Jörg Hundenborn, ${ }^{1}$ Steffi Thurig, ${ }^{2}$ Mechthild Kommerell, ${ }^{2}$ \\ Heike Haag, ${ }^{2}$ and Oliver Nolte ${ }^{2,3}$ \\ ${ }^{1}$ Gemeinschaftspraxis für Orthopädie, Chirurgie, Unfallchirurgie Sportmedizin, Manuelle Medizin/Chiropraktik, \\ Theodor Heuss Straße 1, 78467 Konstanz, Germany \\ ${ }^{2}$ Laboratory of Dr. Brunner, Mainaustraße 48 a/b, 78464 Konstanz, Germany \\ ${ }^{3}$ Department of Medical Microbiology and Molecular Microbiology, Laboratory of Dr. Brunner, Mainaustraße 48 a/b, \\ 78464 Konstanz, Germany \\ Correspondence should be addressed to Oliver Nolte; oliver_nolte1965@yahoo.de
}

Received 18 June 2013; Revised 20 August 2013; Accepted 21 August 2013

Academic Editor: Jacques F. Meis

Copyright ( 2013 Jörg Hundenborn et al. This is an open access article distributed under the Creative Commons Attribution License, which permits unrestricted use, distribution, and reproduction in any medium, provided the original work is properly cited.

\begin{abstract}
Marine microorganisms are uncommon etiologies of skin and skin structure infections, that is, wound infections. We report a case of severe wound infection, caused by the marine Photobacterium damselae (Vibrionaceae), in a 64-year-old male patient, returning from Australia. The isolate tested positive for pPHDD1, a plasmid conferring high-level virulence. Furthermore, the wound was coinfected with Vibrio harveyi, a halophile bacterium, which has never been reported from human infections before. Identification was achieved by use of Matrix-Assisted Laser Desorption-Ionization Time of Flight Mass Spectrometry (MALDITOF) and confirmed by $16 \mathrm{~S}$ rDNA sequencing. Data retrieval from bibliography was complicated since $P$. damselae has been renamed often with a number of synonyms present in the literature: Photobacterium damsela, Vibrio damselae, Vibrio damsela, Pasteurella damselae, and Listonella damsela. With all synonyms used as query terms, a literature search provided less than 20 cases published worldwide. A majority of those cases presenting as severe wound infection are even fatal following progression into necrotizing fasciitis. Management with daily wound dressing and antibiotic therapy (ofloxacin empirically, followed by doxycycline after availability of microbiology) led in the reported case to a favorable outcome, which seems to be, however, the exception based on a review of the available literature.
\end{abstract}

\section{Introduction}

Global traveling contributes to rapid dispersal of pathogens from regions, where they are endemic to countries, where they have never been seen before. Recent developments in medical microbiology, in particular the Matrix-Assisted Laser Desorption-Ionization Time of Flight Mass Spectrometry (MALDI-TOF) technology [1], enable fast and accurate identifications of bacteria, even of taxa, which are rarely seen or not to be identified by standard identification methods. As a consequence, microbiologists are sometimes facing surprising findings, challenging the microbiology mind on how to interpret these. In the current case report, we present such an unexpected finding, which-upon discussion with the attending surgeon-turned out to be a zoonosis of uncommon etiology, caused by marine bacteria of the family Vibrionaceae.

Despite their relative infrequency, zoonotic infections by members of the Genus Vibrio are well known. Between 1981 and 1993 a total of 168 cases of wound infections (85 of these required hospitalization) were reported from Florida. Vibrio parahaemolyticus (33.3\%), Vibrio vulnificus (28.0\%), 
and Vibrio alginolyticus (22.0\%) were the most frequently isolated species. Out of the hospitalized patients, 9.4\% had a fatal outcome. Other Vibrio species, isolated from zoonotic wound infections, were Vibrio cholerae (O1 and non-O1 isolates), Vibrio hollisae (in the meantime renamed to Grimontia hollisae), Vibrio fluvialis, Vibrio mimicus, Vibrio damsela, and Vibrio metschnikovii. Further Gram-negative marine bacteria such as Aeromonas hydrophila may cause wound infections as well $[2,3]$. Infections due to the two most frequent bacteria, $V$. parahaemolyticus and V. vulnificus, have recently been identified as an increasing and important clinical problem in Europe [4]. Physicians must be aware that in patients presenting with wound infections and reporting contact to seawater and fish or exposure to seafood, the abovementioned Vibrio species may be the cause of infection. In such cases, early empiric antibiotic treatment is required [3], and bacteriology is imperative. In order to guarantee accurate diagnostic service, it is mandatory to include as much information as possible into the diagnostic request to enable the microbiologist to interpret the findings of bacteriology.

\section{Case Description}

The microbiology unit of a routine laboratory received a wound swab for bacteriology examination. The swab was taken prior to antimicrobial treatment from the infected wound of a 64-year-old male patient. Wound infection at the lower leg was recorded on the documents accompanying the swab, and bacteriology including susceptibility testing was requested. Two highly unusual microorganisms, Photobacterium damselae and Vibrio harveyi, were isolated. The microbiologists' first suspicion of the patient being a fisherman at the nearby Lake of Constance became unlikely upon identification of $V$. harveyi, since this microorganism is a halophilic inhabitant of seawaters. In fact, the 64year-old male, athletic, and sportive patient without known underlying conditions had a travel history. He presented with an infected wound following return of a vacation in Western Australia. There, he had been active in aquatics and had done a boat tour in the Indian Ocean near the estuary of Murchison River. He got a laceration injury at the forefront of his right tibia, after falling off a catamaran and having had contact with the sharp-edged keel. The patient consulted a local hospital where the wound was closed with a suture. No antimicrobials were prescribed, and he was discharged from ambulatory care. However, the wound developed signs of inflammation, and the patient presented at a local tertiary hospital upon his return to Germany one week later. Topical ointment and change of bandage were performed. Since the inflammation progressed, the suture was removed and the wound was opened for drainage. Following renewal of the ointment the patient was sent to the surgeon office of one of the authors for continuation of wound management. Here, a wound of approximately $30 \times 20 \mathrm{~mm}$ in size with a reddish margin of about $60-70 \mathrm{~mm}$ was dressed by daily ambulant care. The wound presented at this first visit on day 8 after the injury with necrotic areas and a superficial smear. However, the
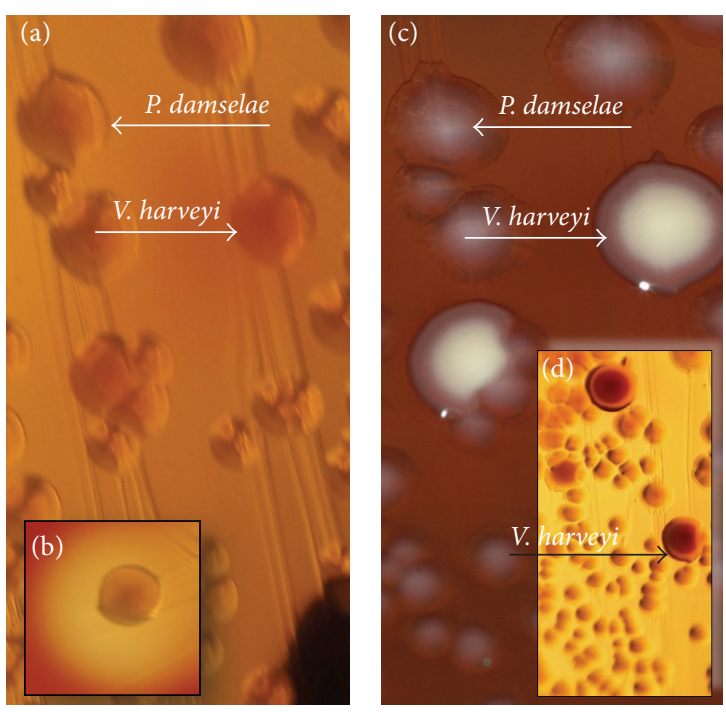

Figure 1: Growth of P. damselae and V. harveyi on Columbia agar, (a) following 24 and (c) following approximately $48 \mathrm{hrs}$ of incubation, as observed from the original inoculation. The colony marked with $V$. harveyi in (c) has a diameter of $2-3 \mathrm{~mm}$. Note that (a), (b), and (d) were taken with flash against transmitting sunlight while (c) was taken with flashlight from above only. The section in (a) shows the growth after $24 \mathrm{hrs}$ at $35 \pm 1^{\circ} \mathrm{C}$, and (b) is taken at the same time, but illustrating the hemolysis of $P$. damselae. (c) was taken following additional $24 \mathrm{hrs}$ of incubation, however, at room temperature. While the images (a) and (c) show almost identical sections of the agar plates, they are not superimposable due to variations in the position. (d) illustrates the differences in color, seen especially after approximately $48 \mathrm{hrs}$, when $V$. harveyi was allowed to grow at a more ambient temperature (i.e., room temperature).

patient did not show any systemic symptoms like fever, chills, and so forth. Therefore, surgical wound debridement was done, and ethacridine ointment (Rivanol) was applied. Following swabbing for microbiological investigation, empiric antibiotic treatment with ofloxacin (Tarivid), $200 \mathrm{mg}$ twice daily, was initiated.

\section{Bacteriology}

Upon receipt of the swab, culture was initiated following standard procedures. Columbia, MacConkey, and Schaedler agar (bioMérieux, Marcy l'Etoile, France) were inoculated automatically by use of WASP instrument (Copan, Italy). At the first visual inspection of the aerobically $\left(5 \% \mathrm{CO}_{2}\right.$ atmosphere, $35 \pm 1^{\circ} \mathrm{C}$ ) incubated Columbia agar plate after 18-20 hrs, moderate growth of medium-sized, flat, light-grey colonies with extensive $\beta$-hemolysis was observed. Identification was done, and the plates were left aside for further $24 \mathrm{hrs}$. With the second visual inspection, few additional larger colonies became apparent, which were not distinguished with the previous reading of the plates (Figure 1). These colonies impressed, in transmitting light, with a red-colored center.

The hemolytic bacteria were identified by use of MALDIBiotyper MALDI-TOF instrument (Bruker Daltonics, Bremen, Germany), as being $P$. damselae, while-on the next 
TABLE 1: MALDI-TOF identification results obtained for $P$. damselae and $V$. harveyi. Note that the number of available spectra in the database is 4 for $P$. damselae (two for each subspecies) and 4 for $V$. harveyi. MALDI scores equal or higher than 2.000 allow for the designation of a species while below 2.000 but equal or above 1.700 allow for the designation of a genus. By default, 10 hits per identification are provided. Hits with scores in support of the final identification are given in bold. The installed database was V3.3.1.0_4110-4613 as of August 2012.

\begin{tabular}{ll}
\hline Matching spectra: & Score \\
\hline Photobacterium damselae ssp. piscicida PC846_1 & $\mathbf{2 . 1 7 6}$ \\
EGS & \\
Photobacterium damselae ssp. piscicida ATCC & $\mathbf{2 . 1 5 5}$ \\
29690 EGS & \\
Photobacterium damselae ssp. damselae DSM & $\mathbf{2 . 1 5 1}$ \\
7482T HAM & \\
Photobacterium damselae ssp. damselae CDC & 1.786 \\
2227_81 EGS & 1.427 \\
Enterobacter cloacae 20105_2 CHB & 1.358 \\
Pseudomonas fluorescens DSM 50090T HAM & 1.328 \\
Klebsiella pneumoniae ssp. ozaenae CCM 5792T & 1.289 \\
CCM & 1.279 \\
Kocuria rosea IMET 11363T HKJ & 1.275 \\
Comamonas nitrativorans DSM 13191T HAM & 2.210 \\
Leuconostoc mesenteroides Ssp. cremoris DSM 20200 & 1.935 \\
DSM & 1.856 \\
Vibrio harveyi DSM 19623T DSM & 1.850 \\
Vibrio alginolyticus CCM 7037 CCM & 1.840 \\
Vibrio harveyi LMG 19643T HAM & 1.825 \\
Vibrio mytili DSM 19137T LGL & 1.818 \\
Vibrio parahaemolyticus DSM 10027T DSM & 1.744 \\
Vibrio parahaemolyticus DSM 11058 DSM & 1.732 \\
Vibrio alginolyticus DSM 2171T DSM & \\
\hline & \\
\hline Vibrio alginolyticus CCM 2578T CCM & \\
\hline
\end{tabular}

day-the nonhemolytic large colonies were classified as being $V$. harveyi (MALDI-TOF scoring shown in Table 1). While $P$. damselae was found to be catalase negative, with weak reaction against oxidase reagent, $V$. harveyi was positive in both biochemical tests. Both bacteria impressed in the Gram stain as short, partly coccoid but rod-shaped microorganisms.

\section{Molecular Characterization}

In case of rarely encountered species, $16 \mathrm{~S}$ rDNA sequencing is applied in our laboratory within a course of extended validation of the comparatively new technique of mass spectrometry in routine bacteriology. DNA was therefore extracted from single colonies and the $5^{\prime}$ part of the $16 \mathrm{~S}$ rDNA amplified as previously described [5]. Primer $27 \mathrm{f}$ was used for sequencing, which was done at a commercial sequencing unit in Constance (gatc Biotech, Constance, Germany). Sequences were checked carefully and edited where necessary. Each sequence was BLASTed against the NCBI database [6], with the online tool SepsiTest BLAST [7] and with the "Lightened Version Bio Informatic Bacteria Identification" tool (LeBIBI) $[8,9]$. The sequence matched $100 \%$ (length of sequence 876 nucleotides) with the GenBank deposited sequence of $P$. damselae, isolate Mm041 [gi|334352811] and 99.9\% (873 of 874 nucleotides) with that of $P$. damselae ssp. damselae in the SepsiTest BLAST database.

Identification of the second micro-organism was ambiguous in the SepsiTest BLAST database since two hits with identical scores of $99.9 \%$ were found, V. harveyi and Vibrio rotiferanus, while NCBI BLAST provided with 99.9\% identity to published sequences $V$. harveyi and Vibrio communis.

Based on the combined results of MALDI-TOF and 16S rDNA analysis, we reported $P$. damselae and $V$. harvey $i$ as final identification.

In order to examine as to whether the $P$. damselae isolate was of the highly virulent genotype, we subsequently used primer F-P.dam-3 [10] and our newly designed primer RP.dam-5 (5' ATCGAACAGTATGCTCTAGGCT $\left.3^{\prime}\right)$ to successfully amplify a 366 bp subgenic fragment of the plasmid located $d l y$ gene. Sequencing of the amplicon in both directions showed a $100 \%$ match with the only available Genbank sequences gi|311872675 (Photobacterium damselae subsp. damselae virulence plasmid pPHDD1, complete sequence, isolate RM71) and gi|295427 (Vibrio damsela phospholipase D (dly) gene, complete cds).

\section{Susceptibility Testing}

The presence of $\beta$-lactamase genes in members of the family Vibrionaceae has been reported recently [11]. The P. damselae isolate was tested on MUELLER-HINTON agar, and the inhibition zones were automatically recorded using the SirScan instrument (i2a, Pérols Cedex, France). Since the genus Photobacterium is a member of the family Vibrionaceae, interpretation of the inhibition zones (Table 2) was done using the CLSI guidelines for Vibrio ssp. (excluding Vibrio cholerae), which are implemented in the Sirweb expert system (i2a, Pérols Cedex, France), operated in our unit. The $V$. harveyi isolate could not be tested since it did not grow sufficiently at $35^{\circ} \mathrm{C}$ on MUELLER HINTON agar.

\section{Final Outcome}

The wound improved well under empiric ofloxacin therapy and daily care (debridement) (Figure 2). Following report of microbiological results, the antibiotic regime was changed to $100 \mathrm{mg}$ doxycycline twice daily (one of the antimicrobials recommended in the treatment of Vibrio vulnificus infections [12]) for another 10 days. Surgical wound debridement continued overall for three weeks. The wound healed without further complications though it took 14 weeks until complete closure of the wound was noticed. 
TABLE 2: Result of disc diffusion test (except amikacin, which was tested with E-Test) with $P$. damselae on MuelLER-Hinton agar after 24 hrs of incubation at $35 \pm 1^{\circ} \mathrm{C}$. The antimicrobials tested are those routinely used for Gram-negative isolates in the laboratory of one of us. The categorical interpretations (S: susceptible; R: resistant) are based on the CLSI recommendation for Vibrio ssp. (excluding Vibrio cholerae) as implemented in the Sirweb software (i2a, Pérols Cedex, France). Antimicrobials capitalized with “*” are those recommended for firstline testing, those in CAPITALS indicate antimicrobials recommended for testing, and those in italics are antibiotics tested routinely in our lab with Gram-negatives on Mueller Hinton agar, but are not recommended by Clinical and Laboratory Standard Institute (CLSI) when testing Vibrio species. (n.a.: not applicable).

\begin{tabular}{|c|c|c|c|c|}
\hline \multirow{2}{*}{ Antimicrobial } & \multirow{2}{*}{ Disc concentration $(\mu \mathrm{g})$} & \multicolumn{2}{|c|}{ Inhibition zone diameter $(\mathrm{mm})$} & \multirow{2}{*}{$\begin{array}{c}\text { Categorical interpretation } \\
\text { based on zone }\end{array}$} \\
\hline & & Observed & $\begin{array}{c}\text { Zone diameter } \\
\text { breakpoint }\end{array}$ & \\
\hline AMPICILLIN & 10 & 24 & $\geq 17$ & $S$ \\
\hline AMPICILLIN/ClAVULANIC ACID & $20 / 10$ & 25 & $\geq 15$ & S \\
\hline AMPiCILLIN/SULBACTAM & $10 / 10$ & 24 & $\geq 18$ & S \\
\hline PIPERACILLIN/TAZOBACTAM & $100 / 10$ & 30 & $\geq 21$ & S \\
\hline Cefaclor & 30 & 31 & n.a. & n.a. \\
\hline Cefotaxime & 30 & 29 & $\geq 23$ & S \\
\hline Cefoxitin & 30 & 24 & $\geq 18$ & S \\
\hline Cefpodoxime & 10 & 26 & n.a. & n.a. \\
\hline Ceftazidime $^{*}$ & 30 & 30 & $\geq 18$ & S \\
\hline IMIPENEM & 10 & 26 & $\geq 16$ & S \\
\hline MERopenem & 10 & 13 & $\geq 16$ & $\mathrm{R}$ \\
\hline Ciprofloxacin* & 5 & 30 & $\geq 21$ & S \\
\hline LEVOFLOXACIN* & 5 & 28 & $\geq 17$ & S \\
\hline AMIKACIN & $E$-test & $2 \mathrm{mg} / \mathrm{L}$ & $\leq 16 \mathrm{mg} / \mathrm{L}$ & S \\
\hline GENTAMiCIN & 10 & 17 & $\geq 15$ & S \\
\hline SULFAMETHOXAZOLE & $1.25 / 23.75$ & 22 & $\geq 16$ & S \\
\hline TETraCyCline $^{*}$ & 30 & 28 & $\geq 19$ & S \\
\hline Nitrofurantoin & 300 & 24 & n.a. & n.a. \\
\hline
\end{tabular}

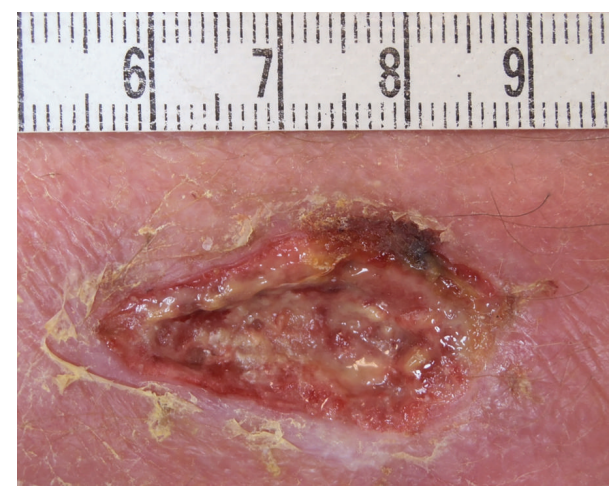

FIGURE 2: Wound, following seven days of ofloxacin (Tarivid) and following daily debridement, eight days after opening by removing the surgical threat. (Bar at the top is in $\mathrm{cm}$.)

\section{Discussion}

The subspecies piscicida of the bacterium $P$. damselae is a very well-studied fish pathogen, causing a disease known as "fish pasteurellosis" [23]. Human diseases caused by $P$. damselae subspecies damselae (originally described as Vibrio damsela [24]) are rare, with less than 20 patients reported in the literature. Like other Vibrionaceae species its natural habitat is seawater. The second microorganism reported here, $V$. harveyi, is considered nonpathogenic to humans [25]. However, the bacterium was recovered from the wound more than one week after the initial injury and the presumed contact with this bacterium. Under laboratory conditions, $V$. harveyi shows optimal growth at $20^{\circ} \mathrm{C}$ [26]. During our routine work, a reduced growth rate at $35^{\circ} \mathrm{C}$ was observed (susceptibility test could not be read due to sparse growth). It seems therefore not very likely that $V$. harveyi is able to proliferate in human tissue. Therefore, the actual role of this micro-organism in the etiology of the wound infection remains unclear, with a role as colonizing bacterium being equally likely as a role as (secondary) pathogen. While mixed infections with $P$. damselae and $V$. parahaemolyticus or $V$. alginolyticus have been mentioned in the literature [2], the case reported here, presenting as a mixed infection of $P$. damselae with $V$. harveyi, is to the best of our knowledge the first one reported in the literature. Since the patient denied having taken antibiotics following the initial hospital visit it is likely that the isolated microorganisms were those solely accountable for the infection.

A number of case reports of $P$. damselae wound infections have been published [13-22, 27], and the described infections were mostly severe, in the majority of those cases, and even 
TABLE 3: Review of the available human cases of severe wound infections* , caused by P. damselae (for other synonyms found in the literature refer to the discussion section).

\begin{tabular}{|c|c|c|c|c|c|}
\hline Patient & Age & Type of injury, other conditions & Clinical course & Outcome & Reference \\
\hline Male & 58 & $\begin{array}{l}\text { No obvious injury reported, swollen } \\
\text { hand after fishing, and diabetes } \\
\text { mellitus }\end{array}$ & $\begin{array}{l}\text { Postsurgical complications, } \\
\text { cardiac arrest }\end{array}$ & Fatal & {$[13,14]$} \\
\hline Male & 76 & Minor puncture at thumb & $\begin{array}{l}\text { Wound, progressing to } \\
\text { necrotizing fasciitis (NF), } \\
\text { intravascular coagulation, septic } \\
\text { shock }\end{array}$ & Fatal & {$[13]$} \\
\hline Male & 69 & $\begin{array}{l}\text { Partially healed laceration (finger) and } \\
\text { fishhook injury (finger) } 2 \text { weeks prior } \\
\text { to onset }\end{array}$ & NF, multiple organ failure & Fatal & {$[15]$} \\
\hline Male & 43 & $\begin{array}{l}\text { Laceration by stingray when stepping } \\
\text { off a boat }\end{array}$ & Fever, erythema, followed by NF & $\begin{array}{l}\text { Cured (deep surgical } \\
\text { debridement) }\end{array}$ & [16] \\
\hline Male & 64 & $\begin{array}{l}\text { Injury from fish hook, atherosclerotic } \\
\text { heart disease, and ventricular } \\
\text { arrhythmias }\end{array}$ & $\begin{array}{l}\text { Erythema and profound edema, } \\
\text { postsurgical complications, acute } \\
\text { renal failure }\end{array}$ & Fatal & {$[17]$} \\
\hline Male & 63 & $\begin{array}{l}\text { No injury recorded, consumption of } \\
\text { raw eel, diabetes mellitus, alcoholic, } \\
\text { liver disease }\end{array}$ & $\begin{array}{l}\text { Swelling and erythema on arm } \\
\text { and hand, NF, intravascular } \\
\text { hemolysis, septic shock }\end{array}$ & Fatal & {$[18]$} \\
\hline Male & 70 & $\begin{array}{l}\text { Knife cut after handling bluefish, } \\
\text { previously healthy, mitral valve } \\
\text { replacement and coronary artery } \\
\text { bypass }\end{array}$ & $\begin{array}{l}\text { Wound infection, fever and } \\
\text { swelling of the hand, sepsis }\end{array}$ & Fatal & [19] \\
\hline Male & 62 & $\begin{array}{l}\text { Puncture wound at thenar following } \\
\text { rabbitfish fin injury }\end{array}$ & $\begin{array}{l}\text { Swollen forearm with dusky } \\
\text { discoloration, progressing into } \\
\text { NF, renal failure, septic shock }\end{array}$ & Fatal & {$[20]$} \\
\hline Male & 38 & Fish fin puncture & erythema and edema, severe pain & Cured by amputation & {$[21]$} \\
\hline Male & 61 & $\begin{array}{l}\text { Minor injury while cleaning catfish, } \\
\text { alcoholic, and diabetes mellitus }\end{array}$ & $\begin{array}{l}\text { NF, intravasal coagulation, renal } \\
\text { failure, cardiac arrest }\end{array}$ & Fatal & {$[22]$} \\
\hline Male & 64 & $\begin{array}{l}\text { Laceration injury in marine } \\
\text { environment }\end{array}$ & $\begin{array}{l}\text { Wound infection with local } \\
\text { necrosis }\end{array}$ & Cured & This report \\
\hline
\end{tabular}

${ }^{*}$ Another six cases of $P$. damselae wound infections are given in [2] without enough information to be included in this table.

fatal. The clinical presentation was predominantly necrotizing fasciitis, a condition requiring fast medical response, that is, surgery and/or amputation [15]. Table 3 summarizes relevant information on severe wound infections caused by $P$. damselae as extracted from the available literature [13-22]. Taking this into account, the patient described in our case report showed a very favorable outcome.

Beside infections as a consequence of lacerations or other minor injuries, infections following oral ingestion provide the second way of developing this zoonosis [28].

It should be noted, however, that in the literature prior to 2004 the older synonyms were used, making literature search cumbersome. Actually, the species names Photobacterium damselae, Photobacterium damsela, Vibrio damsela, Vibrio damselae, Pasteurella damselae (for the fish disease causing subspecies piscicida), and even Listonella damselae had to be used as search terms to retrieve the published cases.

Human cases might be underreported, given that infections may not be fatal [2]. Prior to the advent of MALDI-TOF in routine laboratories, the identification of Vibrionaceae was hampered by the fact that commercial identification systems showed poor reliability in the identification of members of the genus Vibrio [29]. In our case, the identification of both bacteria was provided conveniently by MALDI-TOF technique. However, Vitek 2 compact, utilizing an identification card for Gram-negatives (GN-card; bioMérieux, Marcy l'Etoile, France), identified $P$. damselae with a very good score as well.

Different from other potentially colonizing bacteria, frequently found in wound swabs, $P$. damselae impresses by its massive $\beta$ hemolysis, which usually would alert the microbiologist to start closer examination of such colonies. Therefore it is not likely that wound infections by this pathogen go by undetected. The hemolytic phospholipase Dly or damselysin has been identified as one of the main virulence mechanisms. However, a correlation of virulence with the strength of hemolysis has been reported. Only strong hemolytic strains are carrying a plasmid, pPHDD1, which encodes for further virulence determinants, necessary to deploy full virulence [30]. Using primers F-P.dam-3 and R-P.dam-5, the expected amplicon of dly was amplified. Thereby it was demonstrated that the isolated $P$. damselae subspecies damselae was positive for plasmid pPHDD1, carrying $d l y$, thus being of the highly virulent type, as was already supposed from the massive hemolysis (Figure $1(\mathrm{~d})$ ). 
It is therefore likely that infections with this bacterium, even with the highly virulent phenotype, do not always progress into the most severe form of necrotizing fasciitis and that other factors, probably individual predisposing factors of the patients, contribute to the outcome of each individual case [3]. Most of the patients with necrotizing fasciitis listed in Table 3 were aged around 60 years or above, and some showed underlying tentatively predisposing conditions like diabetes or alcohol abuse. Interestingly, all were males.

\section{Conclusion}

Our case presentation shows that unusual infections must be suspected in patients returning from abroad and reporting injuries in the countries they have visited. Global travelling nowadays allows taking a bath in the Pacific Ocean and being back at work in Europe not even two days later, providing challenges not only for specialized institutes like departments for tropical medicine but also for office practitioners. Even bacteria supposed to be nonpathogenic, which have marine seawaters as primary habitat, may actually be able to cause disease or at least to participate in infections as has been reported here with the detection of $V$. harveyi. While the etiology reported here is uncommon, severe or fatal infections caused by other vibrionic bacteria are well known. Both $V$. parahaemolyticus and V. vulnificus and, to a lesser extent, $V$. alginolyticus infections have been reported, and it has been discussed that global climate change-among other factorsmay lead to an increase in infections due to marine bacteria $[4,31]$. In view of the high fatality rates observed with wound infections after progressing to necrotizing fasciitis, early and aggressive antimicrobial therapy is essential if Vibrionaceae are suspected. Death may occur as early as $20 \mathrm{hrs}$ after onset of initial symptoms [13]. Bacteriology from adequate specimens is imperative to allow for optional adjustment of therapy following the laboratories report. In the most severe cases, even amputation at a very early stage of disease might be required $[15,19]$.

Modern trends and developments in diagnostics (e.g., MALDI-TOF) allow rapid identification of even unusual pathogens, although frequent taxonomic changes as is the case with $P$. damselae may actually complicate data retrieval. With the wide availability of such techniques it is likely that more infections like the one reported here are detected in the near future. With respect to this, the current case report may add some important information for clinicians as well. Medical microbiologists should always be alerted if MALDITOF analysis yields remarkable identifications.

\section{Conflict of Interests}

The authors declare that they have no conflict of interests.

\section{Authors' Contribution}

Oliver Nolte made the data analysis, supervised the molecular and microbiology work, and wrote the paper, Jörg Hundenborn documented the current case, Mechthild Kommerell made the infectiology consultation, Steffi Thurig has done the MALDI-TOF and susceptibility testing, and Heike Haag did the molecular work. All authors have read and approved the final paper.

\section{References}

[1] P. Seng, M. Drancourt, F. Gouriet et al., "Ongoing revolution in bacteriology: routine identification of bacteria by matrixassisted laser desorption ionization time-of-flight mass spectrometry," Clinical Infectious Diseases, vol. 49, no. 4, pp. 543-551, 2009.

[2] W. G. Hlady and K. C. Klontz, "The epidemiology of Vibrio infections in Florida, 1981-1993," Journal of Infectious Diseases, vol. 173, no. 5, pp. 1176-1183, 1996.

[3] J. D. Oliver, "Wound infections caused by Vibrio vulnificus and other marine bacteria," Epidemiology and Infection, vol. 133, no. 3, pp. 383-391, 2005.

[4] C. Baker-Austin, L. Stockley, R. Rangdale, and J. MartinezUrtaza, "Environmental occurrence and clinical impact of Vibrio vulnificus and Vibrio parahaemolyticus: a European perspective," Environmental Microbiology Reports, vol. 2, no. 1, pp. 7-18, 2010.

[5] L. Lane, "16S/23S sequencing," in Nucleic Acid Techniques in Bacterial Systematics, E. Stackebrandt and M. Goodfellow, Eds., vol. 4, pp. 115-176, John Wiley \& Sons, Chichester, UK, 1991.

[6] "Nucleotide BLAST: Search nucleotide databases using a nucleotide query," http://www.ncbi.nlm.nih.gov/BLAST.

[7] "SepsiTest BLAST_identification by $16 \mathrm{~S} / 18 \mathrm{~S}$ rDNA sequence analysis," http://www.sepsitest-blast.de/en/index.html.

[8] "Lightened version bio informatic bacteria identification-version 5," http://umr5558-sud-strl.univ-lyonl.fr/lebibi/lebibi.cgi.

[9] G. Devulder, G. Perrière, F. Baty, and J. P. Flandrois, "BIBI, a bioinformatics bacterial identification tool," Journal of Clinical Microbiology, vol. 41, no. 4, pp. 1785-1787, 2003.

[10] S. F. González, M. J. Krug, M. E. Nielsen, Y. Santos, and D. R. Call, "Simultaneous detection of marine fish pathogens by using multiplex PCR and a DNA microarray," Journal of Clinical Microbiology, vol. 42, no. 4, pp. 1414-1419, 2004.

[11] L. J. Jun, J. H. Kim, J. W. Jin, and H. do Jeong, "Characterization of a new $\beta$-lactamase gene from isolates of Vibrio spp. in Korea," Journal of Microbiology and Biotechnology, vol. 22, no. 4, pp. 555-562, 2012.

[12] J. Humphrey and L. Richey, "A case series of Vibrio vulnificus infections in New Orleans, Louisiana," The Journal of the Louisiana State Medical Society, vol. 164, no. 4, pp. 197-201, 2012.

[13] K. Yamane, J. Asato, N. Kawade, H. Takahashi, B. Kimura, and Y. Arakawa, "Two cases of fatal necrotizing fasciitis caused by Photobacterium damselae in Japan," Journal of Clinical Microbiology, vol. 42, no. 3, pp. 1370-1372, 2004.

[14] J. Asato and F. Kanaya, "Fatal infection of the hand due to Photobacterium damselae: a case report," Clinical Infectious Diseases, vol. 38, no. 10, pp. e100-e101, 2004.

[15] K. H. Goodell, M. R. Jordan, R. Graham, C. Cassidy, and S. A. Nasraway, "Rapidly advancing necrotizing fasciitis caused by Photobacterium (Vibrio) damsela: a hyperaggressive variant," Critical Care Medicine, vol. 32, no. 1, pp. 278-281, 2004.

[16] G. R. Barber and J. S. Swygert, "Necrotizing fasciitis due to Photobacterium damselae in a man lashed by a stingray," New England Journal of Medicine, vol. 342, no. 11, p. 824, 2000. 
[17] S. L. Fraser, B. K. Purcell, B. Delgado Jr., A. E. Baker, and A. Christian Whelen, "Rapidly fatal infection due to Photobacterium (Vibrio) damsela," Clinical Infectious Diseases, vol. 25, no. 4, pp. 935-936, 1997.

[18] J. H. Shin, M. G. Shin, S. P. Suh, D. W. Ryang, J. S. Rew, and F. S. Nolte, "Primary Vibrio damsela septicemia," Clinical Infectious Diseases, vol. 22, no. 5, pp. 856-857, 1996.

[19] J. Perez-Tirse, J. F. Levine, and M. Mecca, "Vibrio damsela: a cause of fulminant septicemia," Archives of Internal Medicine, vol. 153, no. 15, pp. 1838-1840, 1993.

[20] K.-Y. Yuen, L. Ma, S. S. Y. Wongi, and W.-F. Ng, "Fatal necrotizing fasciitis due to Vibrio damsela," Scandinavian Journal of Infectious Diseases, vol. 25, no. 5, pp. 659-661, 1993.

[21] J. A. Coffey Jr., R. L. Harris, M. L. Rutledge, M. W. Bradshaw, and T. W. Williams Jr., "Vibrio damsela: another potentially virulent marine Vibrio," The Journal of Infectious Diseases, vol. 153, no. 4, pp. 800-802, 1986.

[22] J. E. Clarridge and S. Zighelboim-Daum, "Isolation and characterization of two hemolytic phenotypes of Vibrio damsela associated with a fatal wound infection," Journal of Clinical Microbiology, vol. 21, no. 3, pp. 302-306, 1985.

[23] M. Love, D. Teebken-Fisher, J. E. Hose, J. J. Farmer, F. W. Hickman, and G. R. Fanning, "Vibrio damsela, a marine bacterium, causes skin ulcers on the damselfish Chromis punctipinnis," Science, vol. 214, no. 4525, pp. 1139-1140, 1981.

[24] S. K. Smith, D. C. Sutton, J. A. Fuerst, and J. L. Reichelt, "Evaluation of the genus Listonella and reassignment of Listonella damsela (love et al.) MacDonell and Colwell to the genus Photobacterium as Photobacterium damselae comb. nov. with an emended description," International Journal of Systematic Bacteriology, vol. 41, no. 4, pp. 529-534, 1991.

[25] K. Zhou, M. Gui, P. Li, S. Xing, T. Cui, and Z. Peng, "Effect of combined function of temperature and water activity on the growth of Vibrio harveyi," Brazilian Journal of Microbiology, vol. 43, no. 4, pp. 1365-1375, 2012.

[26] N. Areechon, S. Koydon, and N. Kitancharoen, "Effect of salinity and temperature on the viability of Vibrio harveyi," Kasetsart Journal, vol. 27, no. 1, pp. 67-73, 1993.

[27] J. G. Morris Jr., R. Wilson, D. Hollis et al., "Illness caused by Vibrio damsela and Vibrio hollisae," The Lancet, vol. 319, no. 8284, pp. 1294-1297, 1982.

[28] H. R. Kim, J. W. Kim, M. K. Lee, and J. G. Kim, "Septicemia progressing to fatal hepatic dysfunction in an cirrhotic patient after oral ingestion of Photobacterium damselae: a case report," Infection, vol. 37, no. 6, pp. 555-556, 2009.

[29] C. M. O'Hara, E. G. Sowers, C. A. Bopp, S. B. Duda, and N. A. Strockbine, "Accuracy of six commercially available systems for identification of members of the family Vibrionaceae," Journal of Clinical Microbiology, vol. 41, no. 12, pp. 5654-5659, 2003.

[30] A. J. Rivas, M. Balado, M. L. Lemos, and C. R. Osorio, "The Photobacterium damselae subsp. damselae hemolysins damselysin and HlyA are encoded within a new virulence plasmid," Infection and Immunity, vol. 79, no. 11, pp. 4617-4627, 2011.

[31] G. Sganga, V. Cozza, T. Spanu, P. L. Spada, and G. Fadda, "Global climate change and wound care: case Study of an off-season Vibrio alginolyticus infection in a healthy man," Ostomy Wound Management, vol. 55, no. 4, pp. 60-62, 2009. 


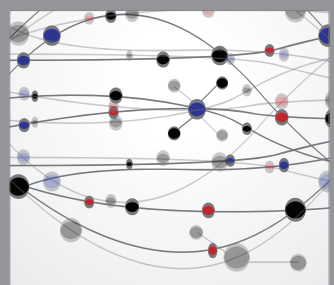

The Scientific World Journal
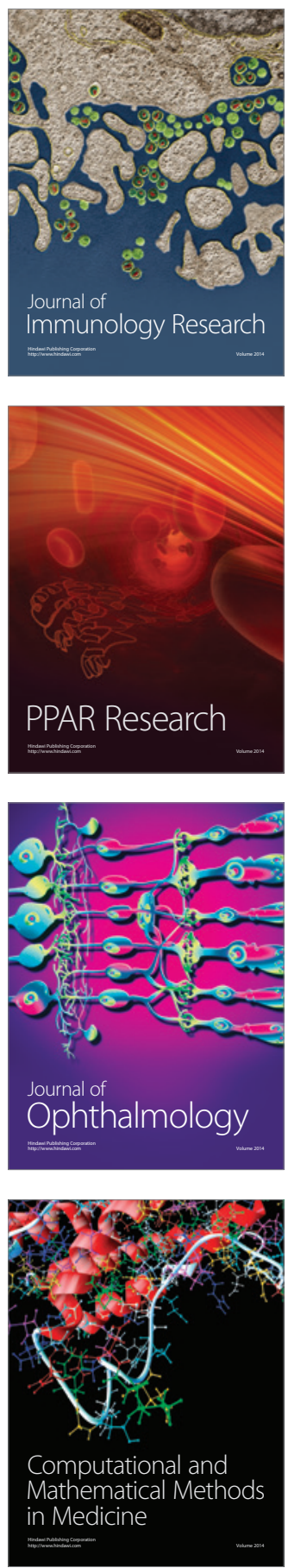

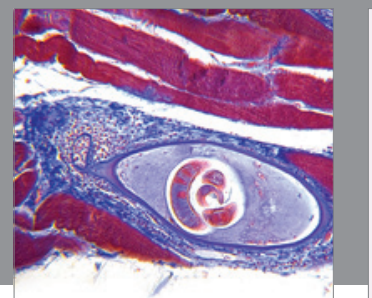

Gastroenterology

Research and Practice
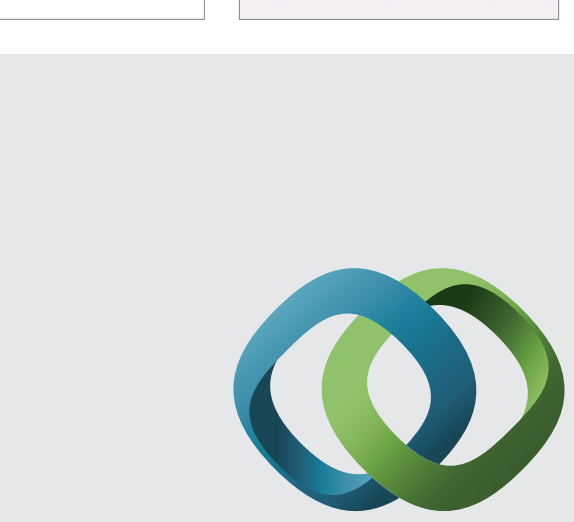

\section{Hindawi}

Submit your manuscripts at

http://www.hindawi.com
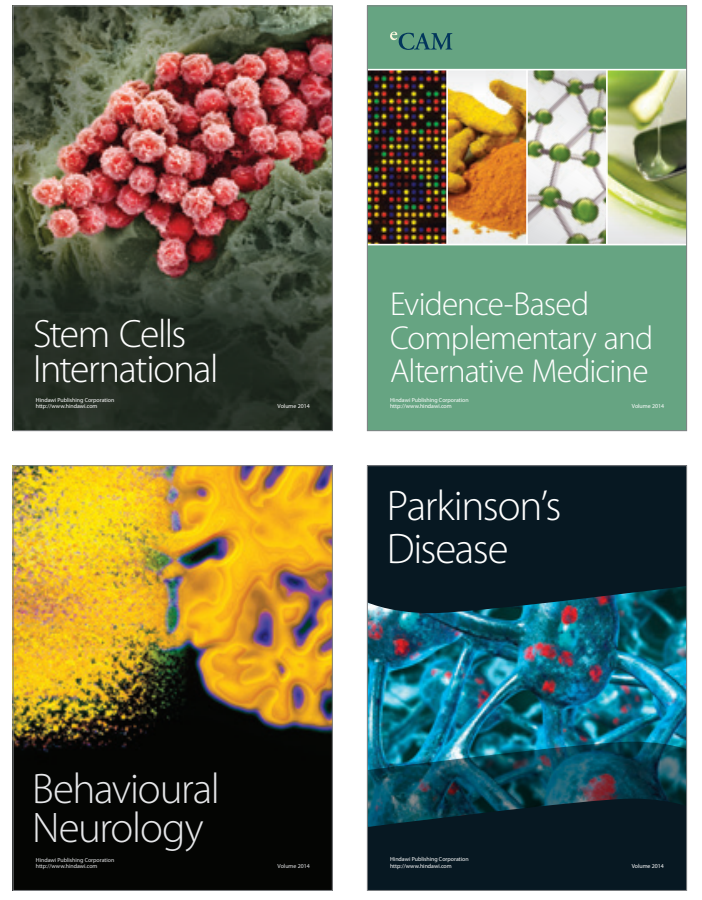
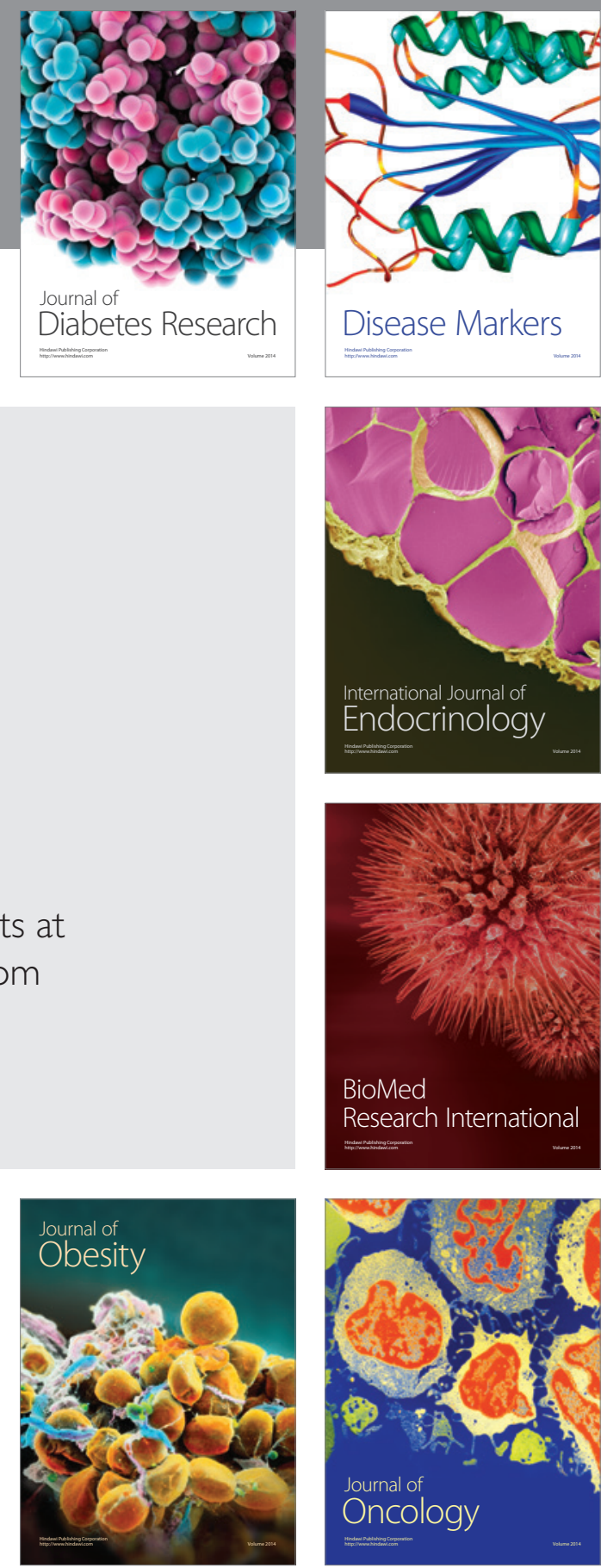

Disease Markers
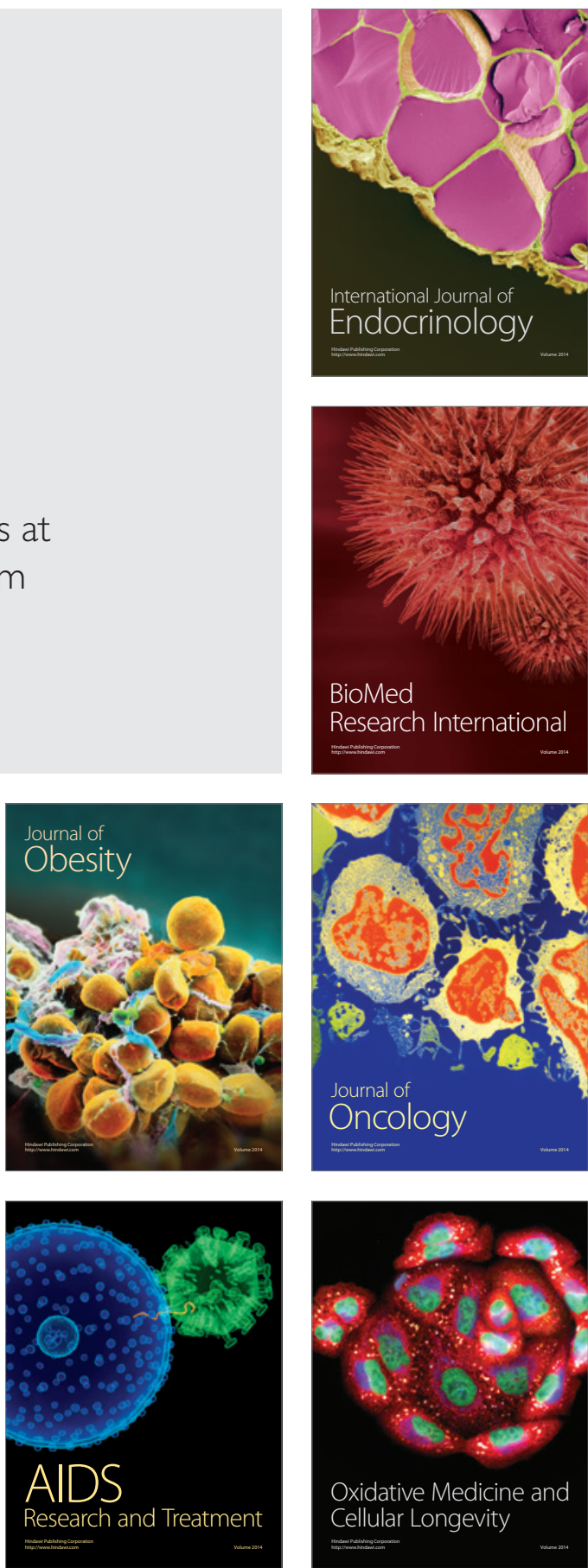